\title{
BMJ Open Copenhagen Airport Cohort: air pollution, manual baggage handling and health
}

Karina Lauenborg Møller, ${ }^{1}$ Charlotte Brauer, ${ }^{2}$ Sigurd Mikkelsen, ${ }^{2}$ Steffen Loft, ${ }^{3}$ Erik B Simonsen, ${ }^{4}$ Henrik Koblauch, ${ }^{4}$ Stine Hvid Bern, ${ }^{2}$ Tine Alkjær, ${ }^{4}$ Ole Hertel, ${ }^{5}$ Thomas Becker, ${ }^{6}$ Karin Helweg Larsen, ${ }^{1}$ Jens Peter Bonde, ${ }^{2}$ Lau Caspar Thygesen ${ }^{1}$

To cite: Møller KL, Brauer C, Mikkelsen S, et al. Copenhagen Airport Cohort: air pollution, manual baggage handling and health. BMJ Open 2017;7:e012651. doi:10.1136/bmjopen-2016012651

- Prepublication history for this paper is available online. To view these files please visit the journal online (http://dx.doi.org/10.1136/ bmjopen-2016-012651).

Received 14 May 2016 Revised 15 January 2017 Accepted 20 January 2017

CrossMark

For numbered affiliations see end of article.

\section{Correspondence to} Dr Karina Lauenborg Møller; kalm@si-folkesundhed.dk.

\section{ABSTRACT}

Purpose: Copenhagen Airport Cohort 1990-2012 presents a unique data source for studies of health effects of occupational exposure to air pollution (ultrafine particles) and manual baggage handling among airport employees. We describe the extent of information in the cohort and in the follow-up based on data linkage to the comprehensive Danish nationwide health registers. In the cohort, all information is linked to the personal identification number that also is used in Denmark Statistics demographic and socioeconomic databases and in the nationwide health registers.

Participants: The cohort covers 69175 men in unskilled positions. The exposed cohort includes men in unskilled jobs employed at Copenhagen Airport in the period 1990-2012 either as baggage handlers or in other outdoor work. The reference cohort includes men in unskilled jobs working in the greater Copenhagen area.

Findings to date: The cohort includes environmental Global Positioning System (GPS) measurements in Copenhagen Airport, information on job function/task for each calendar year of employment between 1990 and 2012, exposure to air pollution at residence, average weight of baggage lifted per day and lifestyle. By linkage to registers, we retrieved socioeconomic and demographic data and data on healthcare contacts, drug subscriptions, incident cancer and mortality.

Future plans: The size of the cohort and the completeness of the register-based follow-up allow a more accurate assessment of the possible health risks of occupational exposure to ultrafine particles and manual baggage handling at airports than in previous studies. We plan to follow the cohort for the incidence of ischaemic heart diseases, cerebrovascular disease, lung and bladder cancer, asthma and chronic obstructive pulmonary disease, and further for associations between heavy manual baggage handling and musculoskeletal disorders.

Trial registration: number 2012-41-0199.

\section{INTRODUCTION}

Globally, more than two million civilian and military personnel are occupationally

\section{Strengths and limitations of this study}

- The size of the cohort and the completeness of the register-based follow-up allow a more accurate assessment of the possible health risks of occupational exposure to ultrafine particles and manual handling at airports than in previous studies.

- The cohort included detailed information on employment for each year.

- The register-based follow-up by linkage to the various nationwide Danish health and population registers ensures an almost complete follow-up.

- Self-reported descriptive data on lifestyle factors were collected among a sample of the study population.

- The main limitation is the impossibility to control for confounder variables such as smoking and other lifestyle factors.

exposed to jet propulsion fuel. ${ }^{1}$ In Copenhagen Airport, the ground personnel perform tasks such as aircraft fuel tanking, security, aircraft parking and towing and baggage handling. ${ }^{2}$ These tasks are often performed in a working environment with high exposure to air pollution, including high levels of ultrafine particles (UFP; diameter $\leq 100 \mathrm{~nm}) .{ }^{3}$ Furthermore, the tasks of baggage handlers include daily heavy lifting of, on average, up to 4-5 tonnes of luggage. ${ }^{4}$

As a part of a large project to improve the air quality of the working environment, the Danish Centre for Environment and Energy at Aarhus University in 2010 measured high number concentrations of particles in open air at Copenhagen Airport. The results showed an average number of 38600 particles $(6-700 \mathrm{~nm}$ in diameter $) / \mathrm{cm}^{3}$, and about $90 \%$ of the measured particles were smaller than $100 \mathrm{~nm}$ (UFP). ${ }^{3}$ Employees working on the apron at Copenhagen Airport were exposed to a number concentration of UFP 
between 12000 and 37000 particles $/ \mathrm{cm}^{3.5}$ The number concentration of UFP was two to three times higher than measured at the kerbside in a traffic loaded street in Copenhagen City Centre during the same period. ${ }^{3}$

For other pollutants $\left(\mathrm{NO}, \mathrm{NO}_{2}, \mathrm{PM}_{2.5}, \mathrm{SO}_{2}\right.$, particle mass, concentration of elemental carbon in the particulate matter, concentration of polycyclic aromatic hydrocarbons in the particulate matter and concentration of volatile organic compounds) with established EU limit values, all levels measured at Copenhagen Airport were below these limits. Air quality limit values for particle number have not been established. ${ }^{6}$

Over the past 10 years, the scientific interest has moved from mass concentration $\left(\mathrm{PM}_{2.5}\right.$ and $\left.\mathrm{PM}_{10}\right)$ to the number concentration of UFP. ${ }^{7}$ UFP differs from larger particles due to the large surface area with adhered toxins and high alveolar deposition. ${ }^{8}$ Several experimental studies in animals have shown that UFP can translocate into the blood vessels due to the small size,$^{8-12}$ and this is likely to occur in humans although translocation from the lungs has not been firmly established. ${ }^{13}$

Ground personnel working on the apron near and around the aircraft are exposed to exhaust from jet fuel and diesel exhaust from handling equipment. ${ }^{3}$ Previous studies have shown that the major sources of UFP are emissions from motor vehicles and other combustion machines. 814

Particulate air pollution has been associated with increased risk of ischaemic heart diseases and various cancers. ${ }^{15-17}$ Previous studies have shown that particulate air pollution increases the risk of hospital admissions due to chronic obstructive respiratory disease. ${ }^{18}{ }^{19}$ Diesel exhaust, which is one of the most prevalent sources of particulate air pollution in urban environments, is an established carcinogen, ${ }^{9}$ mainly based on evidence from occupational exposures among miners. ${ }^{20}{ }^{21}$ There is, however, uncertainty regarding the relation between occupational exposures to particulate air pollution and health problems. ${ }^{22}$ To the best of our knowledge, only two studies have investigated the relation between UFP exposure among employees at civil airports and adverse health effects, and these studies were only based on selfreported data. 2324

It is well documented that the majority of baggage handlers are exposed to a high workload with daily heavy lifting, often in awkward positions, and they report a high prevalence of musculoskeletal disorders, ${ }^{25}$ especially lower back, neck and knee disorders. ${ }^{26-28}$ However, these studies relied on self-reported data about musculoskeletal disorders in small samples and did not include a reference group, and the estimation of exposure was only based on seniority in the occupation and hours per week loading and unloading aircraft. ${ }^{26} 27$

At present, no previous study has analysed the health effects of occupational exposure to UFP or to manual lifting among airport employees using data in a large cohort with complete and long follow-up. The
Copenhagen Airport Cohort includes a unique source of information for occupational epidemiological studies of health effects of high exposure to air pollution and manual baggage handling with follow-up information based on linkage to the Danish nationwide registers. We present the information included in the cohort study and some preliminary data.

\section{COHORT DESCRIPTION \\ Location}

Copenhagen Airport is located $8 \mathrm{~km}$ from the city centre of Copenhagen and is the largest airport in Denmark, with $\sim 22000$ employees working in different companies. In 2015, the total number of international and domestic flights was slightly above 254000 . The apron is the area at the airport where aircrafts are parked, unloaded and loaded, refuelled or boarded (figure 1). ${ }^{5}$

\section{Population and sample size}

The cohort comprises men in unskilled jobs employed at Copenhagen Airport in the period 1990-2012 either as baggage handlers or in other outdoor work on the apron. We created a reference cohort of men in unskilled jobs working indoors at Copenhagen Airport and of men in unskilled jobs working in the greater Copenhagen area without any employment at Copenhagen Airport.

We only included men, as there were few women working as baggage handlers or employed in outdoor work at Copenhagen Airport.

From company employment registers and the union membership registers, we obtained the complete occupational history for each person concerning both present and former employment (figure 2).

Company registers included the two baggage-handling companies at Copenhagen Airport, SAS Ground Service (SAS) and Novia, and CPH Company which owns Copenhagen Airport. For SAS and Novia, we included workers in departments working with baggage handling and doing unskilled work in other departments.

Novia established electronic registers on employees in 1990, and SAS in 1995; using these registers, we identified the relevant workers and their employment period. CPH Company has registered its workers electronically since 1990, and from this company we included security service personnel and other workers in unskilled jobs with a variety of different tasks (eg, area maintenance, certain cleaning tasks, firefighting and marshals).

The workers included in the cohort are organised in three local unions of the National Union of Unskilled Workers (Danish, 3F) and the National Union of Guards and Security Personnel (NUGSP). One of the 3F local unions (3F Kastrup) organises workers in unskilled jobs at Copenhagen Airport and in neighbouring areas of Copenhagen. The two other $3 \mathrm{~F}$ local unions organise workers in unskilled jobs in other areas of greater 


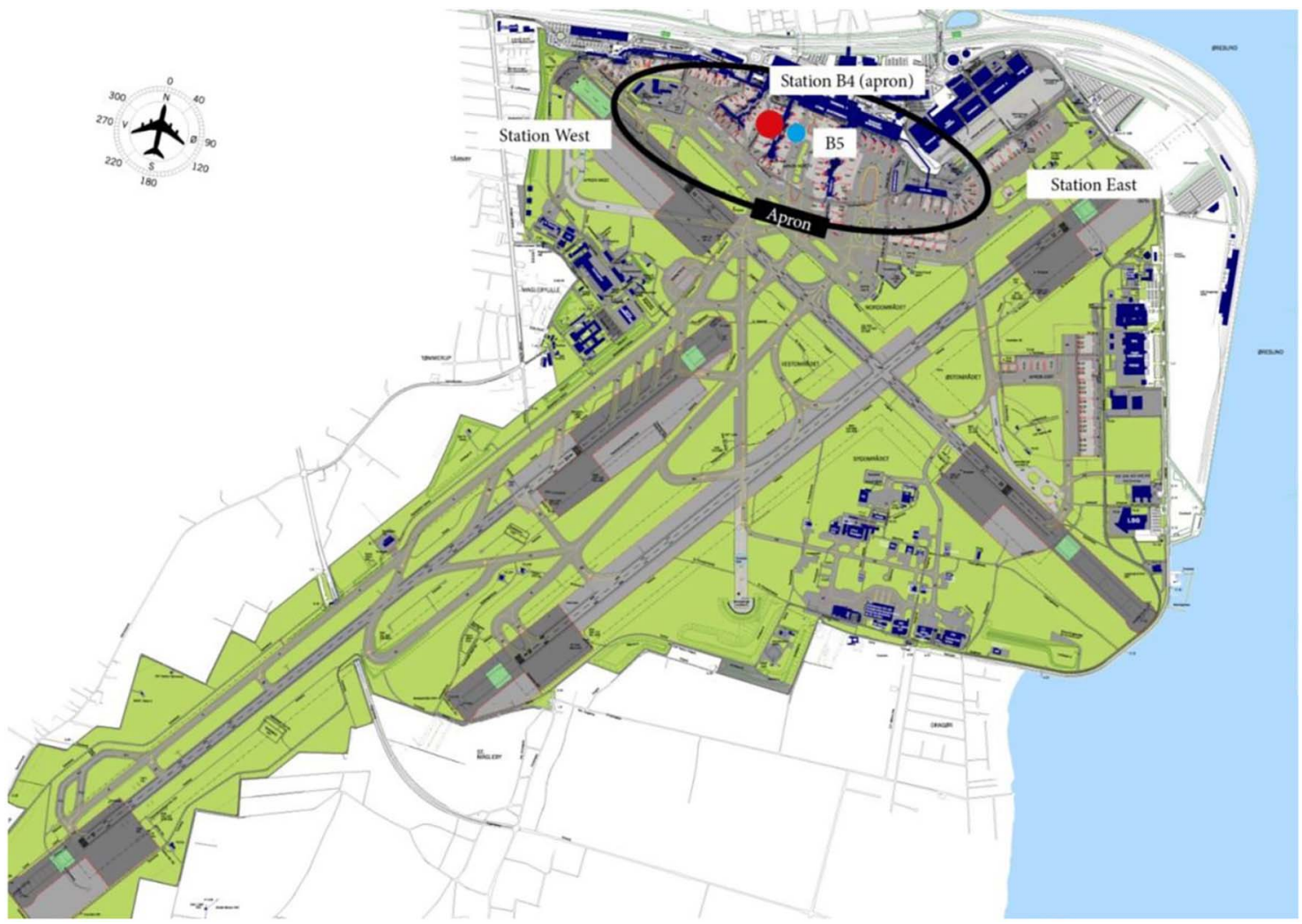

Figure 1 Map of Copenhagen Airport. Reference: Copenhagen Airports A/S.

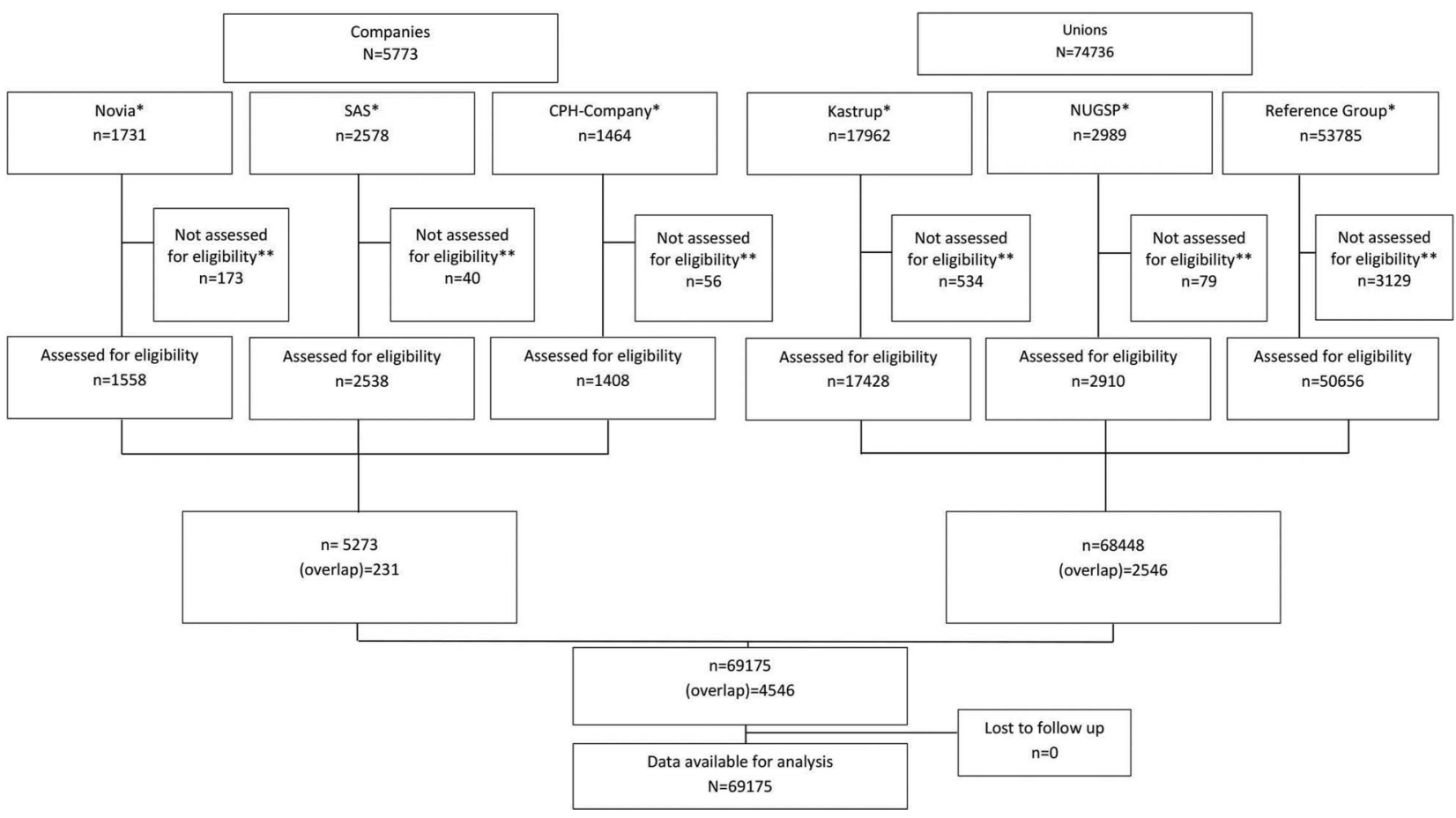

Figure 2 Flow chart of the construction of Copenhagen Airport Cohort. *Novia (Novia Denmark, handling, company), SAS (SAS Ground Service, handling company), CPH (Copenhagen Airport), Kastrup (3F Kastrup—local union), NUGSP (National Union of Guards and Security Personnel), reference group includes $3 \mathrm{~F}$ (Mølleåen, 3F Kastrup and 3F Lager Post and Service Union (LPSF) all organises workers in neighbouring areas of Copenhagen). ${ }^{*}$ Not assessed for eligibility due to: invalid CPR number, missing information on occupation, administrative/management/academic occupations, persons with leave of absence, employment before 15 years of age, men who have never stayed in Denmark under the study period (1990-2012), employment after 31 December 2012, same entry and exit date, dead before employment and dead before 1990. 
Copenhagen. The $3 \mathrm{~F}$ member files are centrally organised, and are electronical for periods of membership (entry and exit dates) back to 1983. The NUGSP organises guards and security personnel and records periods of membership in local unions back to 1979 .

Few persons had entry dates before the member files and company registers became electronic.

In case of overlapping information, we prioritised data in the company register, because it was mandatory for any salary payment, and we included union information if this supplemented the period before the first entry date of company records.

The validity of union information on job function was assessed by calculating the percentage with the same job function recorded in the company registers. We assessed the validity of questionnaire information on job function in the same way. We found good agreement between the data sources, for example, $87 \%$ of persons recorded as baggage handlers by the union were also recorded as baggage handlers in company records, and $92 \%$ of persons who in the questionnaire declared that they had worked as security personnel were recorded as such in the company records.

The company registers comprised information on 5773 men and the union member registers 74736 men. Figure 2 shows the degree of overlapping information. We excluded men using the following criteria: invalid personal identification number, missing information on occupation, same entry and exit dates, administrative/ management/academic tasks, absence leave, employed at an age below 15 years, no permanent residence in Denmark in any year in the study period, only employed after end of follow-up (December 2012), death before employment and death before 1990. After these exclusions, the final study cohort comprised 69175 men in unskilled jobs (figure 2).

At baseline, the reference group worked in a variety of different occupations (eg, municipal workers, drivers, postal workers, garbage collectors, factory workers, etc) ${ }^{29}$ We do not have representative measures of UFP and vehicle exhaustion for the various occupations. However, we are convinced that only a few occupations and few persons in the reference group were continuously exposed to UFP or vehicle exhaust at a similar level as on the apron at Copenhagen Airport. Temporarily, high exposure levels may occur among drivers, garbage collectors, and in the welding and construction industries. However, in the absence of specific exposure information and considering that such groups with potentially high exposures were relatively few, we decided to not to exclude any specific occupations from the reference group. The effect may be a slightly diluted difference in exposure-related effects between the reference group and the exposed group.

\section{Data collection}

Table 1 shows the overview of variables and data collection in the cohort.

\section{Exposure to UFP}

UFP exposure in the airport was estimated based on direct Global Positioning System (GPS) measurements in combination with individual measurements of UFP number concentrations, ${ }^{5}$ expert assessment and comprehensive information on job function and task for each calendar year of employment between 1990 and 2012 .

Among 30 employees from the five largest occupational groups at the airport (baggage handlers, catering drivers, cleaning staff, airside security and landside security staff), we measured time spent on the apron from GPS measurements in combination with personal monitoring of UFP number concentration $\left(\mathrm{n} / \mathrm{cm}^{3}\right)$ during a normal working day. ${ }^{5}$ We found that baggage handlers were exposed to daily average concentrations (geometric mean, GM: $37 \times 10^{3} \mathrm{UFP} / \mathrm{cm}^{3}$ ), which were significantly larger than employees mainly working indoors (GM: $\left.5 \times 10^{3} \mathrm{UFP} / \mathrm{cm}^{3}\right) .{ }^{5}$ Cleaning staff, catering drivers and airside security were exposed to concentrations at the same intermediate level (GM: 12 to $\left.20 \times 10^{3} \mathrm{UFP} / \mathrm{cm}^{3}\right)$. Higher concentrations were measured on the apron compared with other locations at the airport, whether indoors or outdoors. ${ }^{5}$ Therefore, the proportion of daily working hours spent on the apron may serve as a proxy for UFP exposure for occupational groups without UFP and GPS measurements. Five of the occupational groups with measured apron times were used as benchmarks, to assess the average apron times for the remaining occupational groups (see table 2). This was assessed by three airport worker representatives with a comprehensive knowledge of the working procedures for different occupational groups at the airport. In this assessment, the apron times of all drivers, that is, drivers with inflight service, fuel drivers, catering drivers and other inflight and catering personnel, were considered to be similar to that of cleaning staff (measured as $62 \%$ of the time) and differed from the actually measured apron time for catering drivers (measured as $34 \%$ of the time). However, the number concentrations of UFP measured for catering drivers working on the apron was $43 \times 10^{3} \mathrm{UFP} / \mathrm{cm}^{3}$ and for cleaning staff working on the apron $23 \times 10^{3} \mathrm{UFP} / \mathrm{cm}^{3} .5$ The apron time was considered as a proxy for UFP exposure and therefore we assigned the same apron time to this mixed group of drivers, including catering drivers, as that of cleaning staff $(62 \%)$, assuming that these groups had similar exposure to UFP. All other occupational groups were assigned an exposure estimate based on expert assessment of their working time on the apron, expressed as a percentage of daily working time. We pooled groups with similar apron time, resulting in 10 occupational exposure groups with different apron times.

The apron time was calculated for each calendar year as the proportion of time worked on the apron that year according to entry and exit dates for work in specific occupational groups; for example, baggage handling for 150 days, and cargo work for 90 days in a calendar year 
Table 1 Overview of variables and data collection

\begin{tabular}{|c|c|}
\hline Variable & Data collection \\
\hline Personal identification number & $\begin{array}{l}\text { Company and Union registers } \\
\text { Questionnaire } \\
\text { The Danish Civil Registration System } \\
\text { Registers at Statistics Denmark } \\
\text { National Patient Registry } \\
\text { Register of Causes of Death } \\
\text { The Danish National Prescription Registry } \\
\text { Data from Department of Environmental Science, Aarhus } \\
\text { University }\end{array}$ \\
\hline Occupational group* & $\begin{array}{l}\text { Company and Union registers } \\
\text { Questionnaire }\end{array}$ \\
\hline Date for start of employment* & $\begin{array}{l}\text { Company and Union registers } \\
\text { - Questionnaire }\end{array}$ \\
\hline Job function* & $\begin{array}{l}\text { Company and Union registers } \\
\text { Questionnaire }\end{array}$ \\
\hline Physical loads* & $\begin{array}{l}\text { Company statistics } \\
\text { Observations and measurements } \\
\text { Questionnaire }\end{array}$ \\
\hline Date of first hospital contact $†$ & National Patient Registry \\
\hline Diagnosist & National Patient Registry \\
\hline Surgical codes $†$ & National Patient Registry \\
\hline Date of death $\dagger$ & Register of Causes of Death \\
\hline Cause of death $\dagger$ & Register of Causes of Death \\
\hline $\begin{array}{l}\text { Weight, height, leisure time physical activity, smoking status, } \\
\text { alcoholf }\end{array}$ & Questionnaire \\
\hline Educational levelł & Registers at Statistics Denmark \\
\hline Marital status $\ddagger$ & Registers at Statistics Denmark \\
\hline Country of origin $\ddagger$ & Registers at Statistics Denmark \\
\hline Average pollution at residence $\ddagger$ & $\begin{array}{l}\text { Data from the Department of Environmental Science, Aarhus } \\
\text { University }\end{array}$ \\
\hline
\end{tabular}

give $(150 \times 0.76+90 \times 0.25) / 365=0.37$ apron-years of UFP exposure for that year. During follow-up, apron-years were cumulated, resulting in time-dependent apron-years.

\section{Exposure to manual baggage handling}

The level of exposure to manual baggage handling was estimated by direct observations, production statistics from the two handling companies (SAS and Novia), and previous assessments made by the company occupational health service in 1991, 1998 and 2001. In addition, we obtained information about the introduction of technical lifting accessories.

Since 2002 and 2009, SAS and Novia have recorded electronic data on loaded baggage in kilograms $(\mathrm{kg})$ for every single flight. On the basis of these detailed information, we estimate that the average of total baggage lifted per day is $\sim 5000 \mathrm{~kg}$ per baggage handler, slightly less in the baggage sorting area than on the apron, and the average weight of a baggage piece is $\sim 15 \mathrm{~kg}$. Since the beginning of the $1990 \mathrm{~s}$, the daily manual baggagehandling load for each baggage handler has been rather constant over the years.
In addition, we performed biomechanical measurements on a sample of 23 baggage handlers at the airport by monitoring the muscle activity using electromyography over typical working days, including determination of the muscle activity level during specific work tasks.

The handling tasks were also analysed experimentally in a laboratory with video recordings of a baggage handler equipped with a full-body marker set-up performing different handling tasks (eg, standing or kneeling) on force platforms. On the basis of these recordings, inverse dynamics-based musculoskeletal models of the tasks were built in the AnyBody Modeling system V.5.3 (AnyBody Technology A/S, Aalborg, Denmark). ${ }^{30}$ Output from the models was muscle and joint forces. These forces were subsequently used as weights in the register part of the study.

\section{Data sources for outcome variables}

In Denmark, a person's individual identification number is used in the registration of data to the various nationwide registers, and likewise, this individual 
Table 2 Average time spent on the apron (\% of a normal workday) by occupational group

\begin{tabular}{|c|c|c|}
\hline Occupational group & Job description & $\begin{array}{l}\text { Average time on } \\
\text { the apron (\%) }\end{array}$ \\
\hline Baggage handlers* & $\begin{array}{l}\text { Assigned to aircraft procedures on the apron such as } \\
\text { baggage loading and unloading, both inside and } \\
\text { outside the baggage compartment. This group is also } \\
\text { assigned to push the aircraft to the taxiway using a } \\
\text { push-back tractor. }\end{array}$ & 76 \\
\hline Cleaning staff (aircraft cleaners) ${ }^{*}$ & $\begin{array}{l}\text { Assigned to aircraft cabin cleaning. This group goes } \\
\text { into the aircraft from the apron with a diesel powered } \\
\text { high loader, a lorry or from the gate. }\end{array}$ & 62 \\
\hline $\begin{array}{l}\text { Catering drivers, }{ }^{\ddagger} \text { fuel drivers, }{ }^{\dagger} \text { inflight service } \\
\text { drivers }^{\dagger} \text { and other catering and inflight service } \\
\text { personnel }^{\dagger}\end{array}$ & $\begin{array}{l}\text { Catering drivers are assigned to load and unload food } \\
\text { and drinks to and from the aircraft. This group goes into } \\
\text { the aircraft from the apron with a diesel powered high } \\
\text { loader. } \\
\text { Fuel drivers load and service the aircraft with fuel and } \\
\text { handle de-icing. } \\
\text { Inflight service drivers support the aircraft with inflight } \\
\text { service. }\end{array}$ & 62 \\
\hline Push-back ${ }^{\dagger}$ & Aircraft parking/towing & 60 \\
\hline Marshals ${ }^{\dagger}$ & Direct the aircraft to the right gate & 40 \\
\hline Cargo $^{\dagger}$ & Loading and unloading cargo carried by aircrafts & 25 \\
\hline Maintenance service personnel $^{\dagger}$ & Maintain outdoor area (mow the grass, clear snow) & 25 \\
\hline Traffic $^{\dagger}$ gate coordinators ${ }^{\dagger}$ & $\begin{array}{l}\text { Assigned to ensure that all baggage/cargo/mail is } \\
\text { placed correctly and to check the fuel to ensure correct } \\
\text { weight distribution of the aircraft }\end{array}$ & 20 \\
\hline $\begin{array}{l}\text { Airside security (security guards on the } \\
\text { airfield)* }\end{array}$ & $\begin{array}{l}\text { Assigned to security service at the security restricted } \\
\text { area and to patrol by vehicle on the apron, gates and } \\
\text { along fence lines and buildings }\end{array}$ & 14 \\
\hline Firefighters ${ }^{\dagger}$ & On the apron during fire drills & 10 \\
\hline
\end{tabular}

number identifies all persons in the study population of the Airport Cohort.

We linked the cohort with the National Patient Register, the Cancer Registry, the National Prescription Registry and the Register of Causes of Death. ${ }^{31}$ 32-34 The National Patient Register contains data on all inpatients contacts since 1977 and all outpatient and emergency room contacts since $1995 .^{31}$ We retrieved data on hospital contacts due to cardiovascular disease, respiratory diseases and musculoskeletal disorders. Further, data on incident cancer cases were obtained from the Danish Cancer Registry, established in $1943 .{ }^{33}$ Data on drugs prescribed for respiratory diseases were retrieved from the Danish National Prescription Registry, available from $1995 .^{34}$ Data on death and causes of death were retrieved from the Danish Register of Causes of Death, which contains computerised data on all deaths in Denmark of Danish citizens since $1970 .{ }^{32}$

\section{Potential confounders}

Socioeconomic and demographic data

We linked cohort data to Denmark Statistics' various population-based registers. Information on educational level attained in the year before entering the cohort was obtained from the Population Education Register. ${ }^{35}$ Information on country of birth and marital status was obtained from the Civil Registration System. ${ }^{36}$ Information on sickness absence from Coherent Social Statistics $^{37}$ was included, as well as information on any pensioning (disability pensioning, early retirement pension and retirement pension) from the Central Pension Register and Persons who are not in Ordinary Employment. ${ }^{38}$ Information on migration was obtained from the Civil Registration System. ${ }^{36}$

These data sources, the Danish nationwide registers, are updated annually. In the data analyses, the various sociodemographic data were included as timedependent variables.

\section{Lifestyle data}

Self-reported data on health and lifestyle (table 3) were collected by questionnaire. The questionnaires were delivered to all baggage handlers and security service personnel employed in Copenhagen Airport by 1 April 2012. Furthermore, a stratified random sample of the remaining groups (CPH company, NUGSP, 3F Kastrup with other jobs at the airport, 3F Kastrup without work at the airport, and the two other 3F unions (3F Lager 
Table 3 Copenhagen Airport Cohort: baseline characteristics with information from registers and survey

\begin{tabular}{|c|c|c|c|c|c|c|}
\hline \multirow{2}{*}{$\begin{array}{l}\text { Variables } \\
\text { Data from registers }\end{array}$} & \multicolumn{2}{|l|}{ Air pollution } & \multicolumn{2}{|l|}{ Manual lifting } & \multicolumn{2}{|c|}{ Non-respondents in survey } \\
\hline & Reference* $^{*}$ & Exposed $^{\star}$ & Reference† & Exposed $t$ & Respondents & Non-respondents \\
\hline $\mathrm{N}$ & 62546 & 6629 & 65702 & 3473 & 3749 & 1725 \\
\hline Age, median (Q1-Q3) & $31(24-43)$ & $28(24-35)$ & $31(24-43)$ & $27(23-33)$ & $29(24-36)$ & $28(24-35)$ \\
\hline Risk time, person-years & 679385.0 & 51314.2 & 703235.6 & 27463.4 & & \\
\hline Danish country of origin, $n(\%)$ & $51345(83.7)$ & $5529(88.0)$ & 53839 (83.9) & 3067 (89.9) & $3357(89.8)$ & $1386(80.8)$ \\
\hline \multicolumn{7}{|l|}{ Educational level, n (\%) } \\
\hline Elementary school & $35664(57.0)$ & $3132(47.3)$ & 37221 (56.65) & $1575(45.35)$ & $1614(43.1)$ & $873(50.6)$ \\
\hline High school & $8821(14.1)$ & $904(13.6)$ & $9225(14.0)$ & $500(14.4)$ & $565(15.1)$ & $213(12.4)$ \\
\hline Vocational education & $16742(26.8)$ & 2487 (37.5) & $17872(27.2)$ & $1357(39.1)$ & 1494 (39.9) & $610(35.4)$ \\
\hline Higher education & $1319(2.1)$ & $106(1.6)$ & $1384(2.11)$ & $41(1.18)$ & $76(2.0)$ & $29(1.7)$ \\
\hline \multicolumn{7}{|l|}{ Marital status, $n(\%)$} \\
\hline Married & $19663(31.4)$ & $1783(26.9)$ & $20603(31.36)$ & $843(24.27)$ & 1169 (31.2) & $433(25.1)$ \\
\hline Unmarried & 36438 (58.3) & 4459 (67.3) & $38428(58.49)$ & $2469(71.09)$ & 2357 (62.9) & $1185(68.7)$ \\
\hline Divorced & $5712(9.1)$ & $379(5.7)$ & $5932(9.03)$ & $159(4.58)$ & $221(5.9)$ & $102(5.9)$ \\
\hline Widower & $733(1.2)$ & $8(0.1)$ & $739(1.12)$ & $2(0.06)$ & $2(0.1)$ & $5(0.3)$ \\
\hline \multicolumn{7}{|l|}{ Average pollution at residence } \\
\hline Major road within $50 \mathrm{~m}$ of residence, $\mathrm{n}(\%) \ddagger$ & $5593(11.3)$ & $600(10.3)$ & & & & \\
\hline Data from survey & Reference & Exposed & Reference & Exposed & & \\
\hline $\mathrm{N}$ & 1473 & 2276 & 1963 & 1786 & & \\
\hline \multicolumn{7}{|l|}{ Smoking, n (\%) } \\
\hline No & 485 (32.9) & $887(38.5)$ & $680(34.8)$ & $682(38.5)$ & & \\
\hline Former & $507(34.4)$ & $773(34.0)$ & $674(34.5)$ & $606(34.2)$ & & \\
\hline Current & $473(32.1)$ & $609(26.8)$ & $598(30.6)$ & $484(27.3)$ & & \\
\hline Missing & $8(0.54)$ & $17(0.75)$ & $11(0.56)$ & $14(0.78)$ & & \\
\hline \multicolumn{7}{|l|}{ Units of alcohol per week, $\mathrm{n}(\%)$} \\
\hline 0 & $355(24.1)$ & $582(25.6)$ & $502(25.8)$ & $435(24.7)$ & & \\
\hline $1-21$ & $999(67.8)$ & $1567(68.9)$ & $1318(67.8)$ & $1248(70.7)$ & & \\
\hline$>21$ & $106(7.2)$ & $101(4.4)$ & $125(6.4)$ & $82(4.7)$ & & \\
\hline Missing & $13(0.88)$ & $26(1.14)$ & $18(0.92)$ & $21(1.18)$ & & \\
\hline \multicolumn{7}{|l|}{ BMI, n (\%) } \\
\hline$<18.5$ & $8(0.5)$ & $2(0.1)$ & $9(0.47)$ & $1(0.1)$ & & \\
\hline $18.5-25$ & $507(34.4)$ & 795 (34.9) & $685(35.5)$ & $617(35.0)$ & & \\
\hline $25.1-30$ & $664(45.1)$ & $1087(47.8)$ & $892(46.2)$ & $859(48.7)$ & & \\
\hline$>30$ & $267(18.1)$ & $366(16.1)$ & 345 (17.9) & $288(16.3)$ & & \\
\hline Missing & $27(1.83)$ & $26(1.14)$ & $32(1.63)$ & $21(1.18)$ & & \\
\hline
\end{tabular}




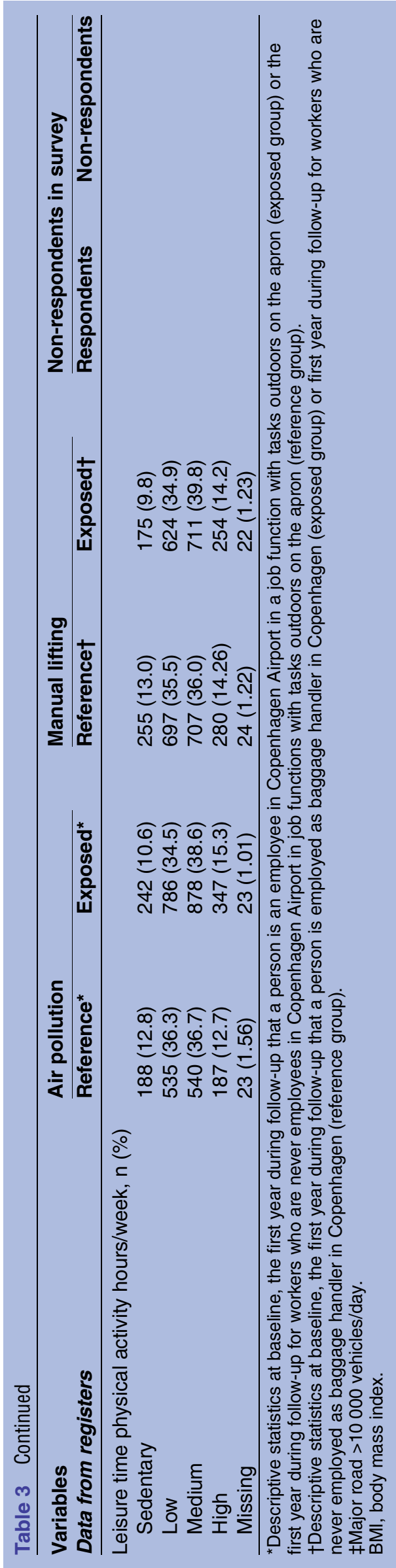

Post and Service Union (LPSF) and 3F Mølleåen) and for previously employed security service personnel). All meet the following criteria: being alive by 1 April 2012, having permanent residence in Denmark, aged 2575 years and not registered as unwilling to participate in research projects (an option by Danish law). The currently employed baggage handlers completed the questionnaire in the airport during their work time, and the others by post. Respondents who did not answer the questionnaire within 3 weeks received a telephone call and were asked to answer the questionnaire by telephone. A total of 3749 men out of 5474 responded to the questionnaire (433 were obtained from telephone interview), making a response rate of $68.5 \%$.

In an analysis of respondents versus non-respondents of the questionnaire, a larger proportion of respondents were Danish of origin, had a higher education and were married (table 3).

\section{Air pollution at residence}

To obtain information on pollution at the residence, all members in the cohort alive on 1 April 2012 were geocoded. We excluded persons with invalid postcodes, individuals who were dead or had emigrated, leaving 57235 addresses. The exact geocodes were identified for 44713 persons. We found invalid geocodes for $299(0.5 \%)$ persons and for 12223 persons we only obtained information about residential address by road, and we therefore imputed the air pollution exposure as the mean exposure for that road. On the basis of the Danish road network and modelled road traffic values, we calculated the distance from residence to the nearest road with annual daily traffic (ADT) of 10000 vehicles or more, and retrieved the ADT value for the identified road segment. In addition, the heavy duty share of the ADT value was also retrieved. Furthermore, the traffic density measure (TDM) within a buffer of $100 \mathrm{~m}$ and $300 \mathrm{~m}$ was assigned to every residence. To calculate the TDM, we applied the following equation:

$$
\mathrm{TDM}=\sum\left(\mathrm{ADT}_{\text {road segment }} \times \text { Length }_{\text {road segment }}\right)
$$

where $A D T_{\text {road segment }}$ is the modelled number of cars on a road segment (eg, between two intersections), and Length $_{\text {rad segment }}$ is the length of the same road segment in metres.

\section{Characteristics of participants}

Table 3 presents baseline characteristics of men exposed to UFP and their reference group and for baggage handlers and their reference group, respectively. At baseline, larger proportions of the reference groups had a higher education and larger proportions of the exposed groups were younger and unmarried. Furthermore, slightly more persons in the reference groups were current smokers. Country of origin, average pollution at residence, alcohol, body mass index and 
leisure time physical activity were similar among the exposed groups and their reference groups.

\section{Analysis methods}

The cohort will be followed from start of employment, 1 January 1990 or immigration after employment, whichever came last, and until first diagnosis of outcome under study, emigration, death or end of follow-up (31 December 2012), whichever came first. This means that cohort members also will be followed after possible end of employment. We will exclude persons with a diagnosis of the outcome under study before 1990 and persons who only had employment after a diagnosis of the outcome under study.

For associations between air pollution data and health outcomes, we will use survival regression models and include the exposure variable in three different models: (1) the exposed group compared with the reference group; (2) apron-years as a categorical variable (nonexposed, 0.1-2.9, 3.0-6.9 and $\geq 7$ years), based on the quantile distribution $(\mathrm{Q} 1=0.8$, median $=2.7$ and $\mathrm{Q} 3=6.7)$;

(3) apron-years as a continuous linear variable adjusted for the binary variable (exposed/reference group) to evaluate the influence of cumulative apron-years among the exposed group.

For the influence of manual lifting, we will include a proxy variable of manual lifting as cumulative years of employment as a baggage handler: (1) baggage handlers compared with the reference group; (2) baggage handler cumulative years categorical (reference group $0.1-2.9,3.0-9.9,10.0-19.9$ years) and (3) cumulative years as a continuous variable.

For both analyses, we will also investigate the nonlinear influence of the exposure variables using restricted cubic spline regression.

\section{Findings until now}

At present, four research papers have been published. ${ }^{4}{ }^{5} 29{ }^{39}$ In the study by Møller et al, ${ }^{5}$ we found that occupational groups who spent the largest amount of time on the apron during a workday also were exposed to the highest mean levels of UFP. Among baggage handlers, we reported that the incidence of subacromial shoulder disorders and meniscal lesions increased with cumulative years of employment ${ }^{29} 39$ and in the study by Bern et $a l,{ }^{4}$ based on self-reported employment history and musculoskeletal pain, the risk of musculoskeletal symptoms in six anatomical regions increased with increasing seniority as a baggage handler.

\section{Strengths and limitations}

The main strengths of the Copenhagen Airport Cohort are the comprehensive data sources used in the construction of the cohort. First, the cohort was constructed on administrative data from company registers and union member registers, which provided detailed information on employment for each calendar year. Thus, recall bias was avoided. Furthermore, it comprises detailed objective information on exposure, and comprehensive register data on outcomes related to health. The size of the cohort is also a strength. The registerbased follow-up by linkage to the various nationwide Danish health and population registers ensures an almost complete follow-up, which may be continued in the future. Finally, the cohort will contribute with longterm follow-up information on health and airport work, which is lacking at present.

The main limitation is the lack of information about a number of important potential confounders, including changing lifestyle over the studied period. Self-reported descriptive data on lifestyle factors were collected among a sample of the cohort. However, these data were crosssectional and only available for 2012 and, for example, smoking habits might have changed over time.

The number concentration of UFP measured on the apron will probably have changed over time due to a wide range of initiatives from Copenhagen Airport, where diesel powered equipment has been replaced by electric equipment. Measurements of UFP were first introduced in 2010 and consequently, UFP levels of today cannot be compared with levels measured back in time. Working time on the apron near the aircraft could have changed during time since new and faster equipment is available today. However, with the increasing number of flights, it is not very likely that the actual working time on the apron is different from the past.

Information from all registers overlap with the cohort except the prescription register, where data are only available since 1995. For this specific register, we may therefore have missed information on drug use dated before 1995, which could lead to truncation bias.

We have information on the full employment history of SAS employees from 1995 and onwards. The lack of electronic data from SAS from 1990 to 1995 means that we have not included employees who stopped their employment before 1995; however, we do not think this may have introduced bias since we have the whole employment history for those included.

Finally, a potential bias of an employed cohort is the healthy worker effect. To diminish this potential bias, we established a reference cohort consisting of men in unskilled jobs other than in airports. ${ }^{40} 41$

\section{Future plans}

We intend to explore correlations between specific morbidity by, for example, ischaemic heart diseases, stroke, lung and bladder cancer, asthma and chronic obstructive pulmonary disease and occupational exposures at airports. In addition, we plan to assess dose-response relationships between heavy lifting, stooped postures and kneeling and musculoskeletal disorders in the low back, shoulders and knees by combining data from the biomechanical measurements with data on handled baggage per day and employment history. Furthermore, 
we will have focus on prognostic studies of musculoskeletal disorders.

We plan to update the cohort by 10 more years in 2022 including information on healthcare contacts by linkage to the national health registers.

\section{Author affiliations}

${ }^{1}$ National Institute of Public Health, University of Southern Denmark, Copenhagen, Denmark

${ }^{2}$ Department of Occupational and Environmental Medicine, Bispebjerg University Hospital, Copenhagen, Denmark

${ }^{3}$ Section of Environmental Health, Department of Public Health, University of Copenhagen, Copenhagen, Denmark

${ }^{4}$ Department of Neuroscience and Pharmacology, University of Copenhagen, Copenhagen, Denmark

${ }^{5}$ Department of Environmental Science, Aarhus University, Roskilde, Denmark ${ }^{6}$ Department of Environmental Science-Emission Modelling \& Environmental Geography, Aarhus University, Roskilde, Denmark

Acknowledgements The authors want to thank Copenhagen Airport, the baggage handling companies, unions and employees in the airport for their invaluable help and support of the study.

Collaborators The researchers would welcome collaboration on future projects. For more information, please contact Charlotte Brauer: Charlotte. Brauer@regionh.dk.

Contributors KLM wrote the first draft of the paper except the section of exposure to manual baggage handling which was written by $\mathrm{CB}$ and the section of air pollution at residence which was written by TB and $\mathrm{OH}$. LCT, $\mathrm{SM}, \mathrm{CB}, \mathrm{KHL}, \mathrm{SHB}$ and $\mathrm{KLM}$ conceived and designed the study. Furthermore, LCT, SM, CB, SHB and KLM contributed to data collection and construction of the cohort. All authors contributed to the critical discussion of data and analyses and all authors revised and approved the final version of the manuscript.

Funding This work was supported by the Danish Working Environment Research Fund (grant numbers 24-2011-03 and 22-2011-09) and the Danish Rheumatism Association (grant number R101-A2003).

Competing interests None declared.

Ethics approval The study was approved by the Danish Data Protection Agency (Journal no: 2012-41-0199).

Provenance and peer review Not commissioned; externally peer reviewed.

Data sharing statement No additional data are available.

Open Access This is an Open Access article distributed in accordance with the Creative Commons Attribution Non Commercial (CC BY-NC 4.0) license, which permits others to distribute, remix, adapt, build upon this work noncommercially, and license their derivative works on different terms, provided the original work is properly cited and the use is non-commercial. See: http:// creativecommons.org/licenses/by-nc/4.0/

\section{REFERENCES}

1. Ritchie G, Still K, Rossi J III, et al. Biological and health effects of exposure to kerosene-based jet fuels and performance additives. $J$ Toxicol Environ Health B Crit Rev 2003;6:357-451.

2. Cavallo D, Ursini CL, Carelli G, et al. Occupational exposure in airport personnel: characterization and evaluation of genotoxic and oxidative effects. Toxicology 2006:26-35.

3. Ellermann T, Massling A, Løfstrøm P, et al. Assessment of the air quality at the apron of Copenhagen Airport Kastrup in relation to the working environment. 2012.

4. Bern SH, Brauer C, Moller KL, et al. Baggage handler seniority and musculoskeletal symptoms: is heavy lifting in awkward positions associated with the risk of pain? BMJ Open 2013;3:e004055.

5. Møller KL, Thygesen LC, Schipperijn J, et al. Occupational exposure to ultrafine particles among airport employees-combining personal monitoring and global positioning system. PLOS ONE 2014;9: e106671.
6. Committee AEES. Ultrafine particles at airports. Discussion and assessment of ultrafine particles (UFP) in aviation and at airports in 2012.

7. Franck U, Odeh S, Wiedensohler A, et al. The effect of particle size on cardiovascular disorders-the smaller the worse. Sci Total Environ 2011;409:4217-21

8. Delfino RJ, Sioutas C, Malik S. Potential role of ultrafine particles in associations between airborne particle mass and cardiovascular health. Environ Health Perspect 2005;113:934-46.

9. Li N, Sioutas C, Cho A, et al. Ultrafine particulate pollutants induce oxidative stress and mitochondrial damage. Environ Health Perspect 2003;111:455-60.

10. Nemmar A, Hoet PH, Vanquickenborne B, et al. Passage of inhaled particles into the blood circulation in humans. Circulation 2002;105:411-14.

11. Donaldson K, Stone V, Seaton A, et al. Ambient particle inhalation and the cardiovascular system: potential mechanisms. Environ Health Perspect 2001;109(Suppl 4):523-7.

12. Oberdorster G, Finkelstein J, Ferin J, et al. Ultrafine particles as a potential environmental health hazard. Studies with model particles. Chest 1996;109(3 Suppl):68s-9s.

13. Rinaldo M, Andujar P, Lacourt A, et al. Perspectives in biological monitoring of inhaled nanosized particles. Ann Occup Hyg 2015;59:669-80.

14. Dominguez-Rodriguez A, Abreu-Afonso J, Rodriguez S, et al. Comparative study of ambient air particles in patients hospitalized for heart failure and acute coronary syndrome. Rev Esp Cardiol 2011:64:661-6.

15. Weichenthal S. Selected physiological effects of ultrafine particles in acute cardiovascular morbidity. Environ Res 2012;115:26-36.

16. Brook RD, Rajagopalan S, Pope CA III, et al. Particulate matter air pollution and cardiovascular disease: an update to the scientific statement from the American Heart Association. Circulationa 2010;121:2331-78.

17. Cancer IAfRo. Outdoor air pollution. IARC monographs on the evaluation of carcinogenic risks to humans. 2015.

18. Andersen ZJ, Hvidberg M, Jensen SS, et al. Chronic obstructive pulmonary disease and long-term exposure to traffic-related air pollution: a cohort study. Am J Respir Crit Care Med 2011;183:455-61.

19. Raaschou-Nielsen $\mathrm{O}$, Andersen ZJ, Hvidberg M, et al. Lung cancer incidence and long-term exposure to air pollution from traffic. Environ Health Perspect 2011;119:860-5.

20. Benbrahim-Tallaa L, Baan RA, Grosse $Y$, et al. Carcinogenicity of diesel-engine and gasoline-engine exhausts and some nitroarenes. Lancet Oncol 2012;13:663-4.

21. Cancer IAfro. IARC monographs on the evaluation of carcinogenic risks to humans. Diesel and gasoline engine exhausts and some nitroarenes. 2012

22. Fang SC, Cassidy A, Christiani DC. A systematic review of occupational exposure to particulate matter and cardiovascular disease. Int J Environ Res Public Health 2010;7:1773-806.

23. Tunnicliffe WS, O'Hickey SP, Fletcher TJ, et al. Pulmonary function and respiratory symptoms in a population of airport workers. Occup Environ Med 1999;56:118-23.

24. Yang CY, Wu TN, Wu JJ, et al. Adverse respiratory and irritant health effects in airport workers in Taiwan. $J$ Toxicol Environ Health Part A 2003;66:799-806.

25. Bergsten EL, Mathiassen SE, Vingard E. Psychosocial work factors and musculoskeletal pain: a cross-sectional study among Swedish Flight Baggage Handlers. Biomed Res Int 2015;2015:798042.

26. Undeutsch K, Gartner KH, Luopajarvi T, et al. Back complaints and findings in transport workers performing physically heavy work. Scand J Work Environ Health 1982:92-6.

27. Rutenfranz J, Lowenthal I, Kylian H, et al. [Occupational health studies on airport transport workers. I. Results of ergonomic time and motion studies (author's transl)]. Int Arch Occup Environ Health 1980:129-41.

28. Stalhammar HR, Leskinen TP, Kuorinka IA et al. Postural, epidemiological and biomechanical analysis of luggage handling in an aircraft luggage compartment. Appl Ergon 1986:177-83.

29. Mikkelsen S, Brauer C, Pedersen EB, et al. A Cohort study on meniscal lesions among airport baggage handlers. PLOS ONE 2016;11:e0157336.

30. Damsgaard M, Rasmussen J, Christensen ST, et al. Analysis of musculoskeletal systems in the AnyBody. J Biomech 2006;14:793-801.

31. Modeling System. Simulation modelling practice and theory. 2006;14:1100-11.

32. Lynge E, Sandegaard JL, Rebolj M. The Danish National patient register. Scand J Public Health 2011(7 Suppl):30-3. 
33. Helweg-Larsen K. The Danish register of causes of death. Scand $J$ Public Health 2011(7 Suppl):26-9.

34. Gjerstorff ML. The Danish cancer registry. Scand J Public Health 2011(7 Suppl):42-5.

35. Kildemoes HW, Sorensen HT, Hallas J. The Danish National Prescription Registry. Scand J Public Health 2011;39(7 Suppl):38-41.

36. Jensen VM, Rasmussen AW. Danish education registers. Scand J Public Health 2011;39(7 Suppl):91-4.

37. Pedersen CB. The Danish civil registration system. Scand J Public Health 2011;39(7 Suppl):22-5.

38. Johansen K, Andersen JS, Mikkelsen S, et al. Controlling sickness absence: a study of changes in the Danish sickness absence legislation since 1973. Health Policy 2008;86:109-18.
39. Baadsgaard M, Quitzau J. Danish registers on personal income and transfer payments. Scand J Public Health 2011;39(7 Suppl):103-5.

40. Thygesen LC, Mikkelsen S, Pedersen EB, et al. Subacromial shoulder disorders among baggage handlers: an observational cohort study. Int Arch Occup Environ Health 2016;89: 867-76.

41. Thygesen LC, Hvidtfeldt UA, Mikkelsen S, et al. Quantification of the healthy worker effect: a nationwide cohort study among electricians in Denmark. BMC Public Health 2011;11:571.

42. Steenland K, Stayner L. The importance of employment status in occupational cohort mortality studies. Epidemiology $1991 ; 2: 418-23$. 